\title{
Housing and Feeding Management Practices in U.S. Nagar District of Uttarakhand, India
}

\author{
Shikha Yadav*, Anil Kumar and C.B. Singh
}

G.B. Pant University of Agriculture \& Technology Pantnagar-263 145, Uttarakhand, India

*Corresponding author

\section{A B S T R A C T}

A study was conducted to evaluate the existing housing and feeding management practices

\section{Keywords}

Feeding, Housing, Management practices, Dairy animals

Article Info

Accepted:

20 May 2019

Available Online:

10 June 2019

followed by the dairy animal keepers in U.S. Nagar district of Uttarakhand. It was observed that majority of farmers housed their animal in pucca house $73.89 \%$, whereas $26.11 \%$ had kaccha houses for their animals. $81.67 \%$ farmers were following group system of animal housing. Kaccha type of floor was found in $54.44 \%$ of the houses. Satisfactory drainage $58.89 \%$ was observed in majority of farmers. $74.44 \%$ of farmers followed permanent type of roof system. 52.22\% farmers housed their animal at day as well as night time. Majority of farmers $60.55 \%$ farmers were followed satisfactory ventilation in their sheds. Regarding feeding practices, majority the farmers followed group feeding $66.67 \%$. Most of the farmers about $90.55 \%$ followed the practice of chopped green fodder and fed dry fodder to their animals. $88.89 \%$ of the farmers fed concentrate to the animals, farmers adopted the practice of feeding cooked $61.11 \%$ form of concentrate to their animals. Most number of farmers $51.11 \%$ preferred readymade sources of concentrate feeding for their animals, more than half $73.89 \%$ of respondents fed colostrum to newly born calf within 2 hours.

\section{Introduction}

Livestock plays an important role in Indian economy. About 20.5 million people depend upon livestock for their livelihood. Livestock contributed $16 \%$ to the income of small farm households as against an average of $14 \%$ for all rural households. Livestock provides livelihood to two-third of rural community. It also provides employment to about $8.8 \%$ of the population in India. Livestock have revolutionized the rural economy of India. It plays an essential and significant role in smallholder subsistence in diverse states of India. Livestock rearing is an important and integral part of agriculture sector in India. It plays significant role in the national economy and socio-economic development of the country. It also plays important role in the economy as supplementing family income and generating gainful employment in the rural sector. Animal husbandry is an occupational culture of livestock production which is making major contribution to 
national economy. The Uttarakhand state possesses 22.35 lacks cattle, 2.19 lacks buffalo, 13.35 lacks goat, 2.90 lacks sheep and 26.01 lacks poultry. Livestock management practices regarding feeding and housing are, the major elements in increasing dairy production. Housing along with feeding management plays a very significant role in animal husbandry (Sinha et al., 2009). Proper housing reduces the incidence of diseases. The present study was undertaken to gather information regarding existing housing and feeding practices adopted by the farmers of U.S. Nagar district and to provide help in scientific management practices in the area.

\section{Materials and Methods}

The present study was undertaken in U.S. Nagar district of Uttarakhand. This district is present in foot hills of kumaon and known as Tarai area also, which is most suitable for crop production. Majority of population depend on agriculture and animal husbandry. The place is located in the foot hills of Himalayas at $28.5^{\circ} \mathrm{SE}$ to $30^{\circ} \mathrm{N}$ Latitudes and $78^{\circ} \mathrm{E}$ to $81^{\circ} \mathrm{E}$ longitude at an altitude of $243.84 \mathrm{~m}$ above mean sea level. State is located in western Himalayan region and is one of the geographically smallest states of the country. The present study was carried out on animals, reared by 180 farmers' viz.: areas of Pantnagar, Gadarpur, Bazpur, Kichha and Sitarganj in Udham Singh Nagar district of Uttarakhand. From each cluster 36 farmers were selected during the period, Jan 2017 to June 2017. The selected farmers were interviewed and the desired information was collected with the help of pre-designed questionnaire. The existing management practices relating to feeding and housing management were separately enlisted. The frequencies were obtained for different housing and feeding management practices included in the study. The score of individual practice was converted into percentage.

\section{Results and Discussion}

\section{Existing housing management practices}

Regarding housing practices the overall results revealed that majority $(73.89 \%)$ of the respondents were housed their animals in pacca house, while $(26.11 \%)$ of the respondents were housed in kaccha house. Sabapara et al (2015), Tewari et al., (2013) who reported that majority of farmers housed their animals in pucca houses in their study. However, findings were contrary to findings revealed by Meena et al., (2008). Most of the respondents kept their animal in group system $(81.67 \%)$ followed by $(18.33 \%)$ were kept in individual type of housing. Housing system followed by majority of farmers $(76.67 \%)$ was semi-intensive followed by extensive (14.44\%) and intensive (8.89\%). Present findings were similar to findings of Garg et $a l .$, (2005). Regarding type of floor more than half $(54.44 \%)$ of the farmers had kachha floor in their sheds followed by $(45.56 \%)$ of the farmers had pucca floor. Similar findings reported by Deoras et al., (2004), Sabapara G.P. et al (2015), Tewari et al., (2013). It is general observation that pucca floor is better than kaccha (mud) floor for their animals to keep them free from worm problems and also from hygienic point of view. Most $(73.89 \%)$ of the respondents had slope in floor in animal shed, findings were similar to Garg et al.(2005), whereas rest $(26.11 \%)$ of the farmers had no slope. More than half of the respondents $(58.89 \%)$ had satisfactory drainage followed by followed by good drainage (24.44\%) and finally poor drainage (16.67\%) There was no significant association between drainage system in animal sheds and clusters, similar findings by Sabapara G.P. et al (2015), Tewari, H. et al., (2013). Majority of the respondents $(74.44 \%)$ had permanent type of roof system followed by temporary $(25.56 \%)$ type of roof. These results are almost similar as observed by Kour (2013). Most of the farmers having pucca manger 
(96.11\%) followed by kaccha $(3.89 \%)$ manger for feeding of their animals. The type of manger was not affected by clusters. Similar findings as observed by Sabapara et al (2010). Most of the cattle and buffalo keepers $(52.22 \%)$ housed their animal at day as well as night followed by night $(29.45 \%)$ and remaining $(18.33 \%)$ were housed in the morning. Majority of the farmers $(47.78 \%)$ had medium sanitation condition followed by good $(31.67 \%)$, poor $(13.33 \%)$ and excellent sanitation conditions (7.22\%) in animal sheds. Findings were similar to findings Sharma and Singh (2003).

Most of farmers $(60.56 \%)$ in different clusters of study had satisfactory ventilation in their sheds followed by good ventilation $(24.44 \%)$ and poor ventilation (15.00\%). This is accordance with the finding of Sabapara et al., (2015) (Table 1).

\section{Feeding management practices}

Majority of the farmers $(66.67 \%)$ preferred group feeding over individual feeding for their animals, $(22.78 \%)$ of the total preferred individual as well as group feeding, remaining $(10.55 \%)$ of the total farmers preferred individual feeding of animals. Findings were similar with the findings of Garg et al., (2005) and Meena et al., (2012).

Majority of the respondents $(65.56 \%)$ animal grazing was never preferred and animals were entirely fed on stall, when grazing was not sufficient then stall feeding was practiced and $(18.89 \%)$ of the farmers preferred animal grazing only when required, while $(15.55 \%)$ of the farmers always took their animals for grazing. Majority of the farmers $(90.55 \%)$ preferred to chop green fodder before feeding it to the animals. Present findings were similar to findings of Hodshil et al., (2007) who reported that chaffing green fodder was adopted by $(36.00 \%)$ farmers, while the present result were contrary with the findings of Meena et al., (2012) who reported that none of the farmers were found to practice fodder chaffing in her study. It was observed that majority $(88.89 \%)$ fed concentrate to the animals while remaining $(11.11 \%)$ of the famers concentrate feeding to the animals was never practiced.

Most number of the farmers $(40 \%)$ preferred feeding of concentrate in morning and $(40 \%)$ of farmers during both morning as well as evening hours, while only a small number of farmers $(20 \%)$ preferred to feed concentrate to their animals during evening. Regarding mode of concentrate feeding $(61.11 \%)$ of respondents fed cooked form followed by wet $(26.11 \%)$ and remaining $(12.78 \%)$ of the farmers' dry form of concentrate feeding is practiced. The results indicated that majority of the respondents $(51.11 \%)$ fed readymade concentrate mixture followed by $(40.56 \%)$ mixture of self made and readymade followed by $(8.33 \%)$ self made.

The results revealed that less number of respondents $(46.67 \%)$ fed mineral mixture to their animals. While less number of the farmers practiced the additions of mineral mixture in the animal ration daily $(21.11 \%)$, whereas maximum percentage of farmer practiced the addition of mineral mixture occasionally $(25.56 \%)$.

Most of the farmers (81.67\%) fed common salt in animal ration daily while, only $(18.33 \%)$ fed occasionally. More than half of the farmers $(73.89 \%)$ out of the total farmers followed colostrums feeding to their animals within 2 hours while, only $(26.11 \%)$ of farmers followed the practice of colostrum feeding to new born between 2 to 4 hours. Present findings were similar to findings of Minu Singh (2015) who reported in their study that Colostrum feeding was followed by most of the respondents (Table 2). 
Table.1 Housing Management practices

\begin{tabular}{|c|c|c|c|}
\hline S.I & Particulars & Frequency & Percentage \\
\hline 1. & \multicolumn{3}{|l|}{ Housing } \\
\hline (a) & Kaccha & 47 & 26.11 \\
\hline (b) & Pacca & 133 & 73.89 \\
\hline 2. & \multicolumn{3}{|l|}{ Type of Housing } \\
\hline (a) & Individual & 33 & 18.33 \\
\hline (b) & Group & 147 & 81.67 \\
\hline 3. & \multicolumn{3}{|l|}{ Housing System } \\
\hline (a) & Intensive & 16 & 8.89 \\
\hline (b) & Semi-Intensive & 138 & 76.67 \\
\hline (c) & Extensive & 24 & 14.44 \\
\hline 4. & \multicolumn{3}{|l|}{ Type of floor } \\
\hline (a) & Kaccha & 98 & 54.44 \\
\hline (b) & Pacca & 82 & 45.56 \\
\hline 5. & \multicolumn{3}{|l|}{ Type of slope } \\
\hline (a) & Yes & 133 & 73.89 \\
\hline (b) & No & 47 & 26.11 \\
\hline 6. & \multicolumn{3}{|l|}{ Drainage } \\
\hline (a) & Good & 44 & 24.44 \\
\hline (b) & Satisfactory & 106 & 58.89 \\
\hline (c) & Poor & 30 & 16.67 \\
\hline 7. & \multicolumn{3}{|l|}{ Roof } \\
\hline (a) & Permanent & 134 & 74.44 \\
\hline (b) & Temporary & 46 & 25.56 \\
\hline 8. & \multicolumn{3}{|l|}{ Manger } \\
\hline (a) & Yes & 180 & 100.00 \\
\hline (b) & No & 00 & 00.00 \\
\hline 9. & \multicolumn{3}{|l|}{ Type of manger } \\
\hline (a) & Kaccha & 7 & 3.89 \\
\hline (b) & Pacca & 173 & 96.11 \\
\hline 10. & \multicolumn{3}{|l|}{ Housing Time } \\
\hline (a) & Day & 33 & 18.33 \\
\hline (b) & Night & 53 & 29.45 \\
\hline (c) & Both & 94 & 52.22 \\
\hline 11. & Sanitation & & \\
\hline (a) & Excellent & 13 & 7.22 \\
\hline (b) & Good & 57 & 31.67 \\
\hline (c) & Medium & 86 & 47.78 \\
\hline (d) & Poor & 24 & 13.33 \\
\hline 12. & Ventilation & & \\
\hline (a) & Good & 44 & 24.44 \\
\hline (b) & Satisfactory & 109 & 60.56 \\
\hline (c) & Poor & 27 & 15 \\
\hline
\end{tabular}


Table.2 Feeding Management Practices

\begin{tabular}{|c|c|c|c|}
\hline S.I & Particulars & Frequency & Percentage \\
\hline 1. & \multicolumn{3}{|l|}{ Feeding } \\
\hline (a) & Individual & 19 & 10.55 \\
\hline (b) & group & 120 & 66.67 \\
\hline (c) & Both & 41 & 22.78 \\
\hline \multicolumn{4}{|l|}{2.} \\
\hline a. & Always & 28 & 15.55 \\
\hline b. & When required & 34 & 18.89 \\
\hline c. & Never & 118 & 65.56 \\
\hline \multicolumn{4}{|l|}{3.} \\
\hline a. & Yes & 180 & 100.00 \\
\hline b. & No & 00 & 00.00 \\
\hline \multicolumn{4}{|l|}{4.} \\
\hline a. & Chopped & 163 & 90.55 \\
\hline b. & Unchopped & 5 & 2.78 \\
\hline c. & Both & 12 & 6.67 \\
\hline 5. & \multicolumn{3}{|l|}{ Mode of Dry fodder } \\
\hline a. & Chopped & 163 & 90.55 \\
\hline b. & Unchopped & 5 & 2.78 \\
\hline c. & both & 12 & 6.67 \\
\hline 6. & \multicolumn{3}{|l|}{ Concentrate feeding } \\
\hline a. & Yes & 160 & 88.89 \\
\hline b. & No & 20 & 11.11 \\
\hline 7. & \multicolumn{3}{|c|}{ Time of concentrate feeding } \\
\hline a. & Morning & 72 & 40 \\
\hline b. & Evening & 36 & 20 \\
\hline c. & Both & 72 & 40 \\
\hline 8. & \multicolumn{3}{|c|}{ Mode of concentrate feeding } \\
\hline a. & As such & 23 & 12.78 \\
\hline b. & Soaked & 47 & 26.11 \\
\hline c. & cooked & 110 & 61.11 \\
\hline 9. & \multicolumn{3}{|c|}{ Source of concentrate feeding } \\
\hline (a) & Readymade & 92 & 51.11 \\
\hline (b) & Self made & 15 & 8.33 \\
\hline (c) & Both & 73 & 40.56 \\
\hline 10. & \multicolumn{3}{|l|}{ Mineral Mixture } \\
\hline (a) & Yes & 84 & 46.67 \\
\hline (b) & No & 96 & 53.33 \\
\hline \multicolumn{4}{|c|}{ If yes then, } \\
\hline a. & Daily & 38 & 21.11 \\
\hline b. & Occasionally & 46 & 25.56 \\
\hline a. & Daily & 147 & 81.67 \\
\hline b. & Occasionally & 33 & 18.33 \\
\hline a. & Within 2 hrs & 133 & 73.89 \\
\hline b. & Between 2-4 hrs & 47 & 26.11 \\
\hline
\end{tabular}


It can be concluded that adoption of scientific existing housing and feeding management practices of dairy animals were close according to the recommended practices. It was observed that overall housing and feeding management practices was satisfactory except for kaccha floor and feeding of mineral mixture so, these practices need to be improved in the survey area. There are few aspects where they followed management practices properly to certain extent but most of the housing and feeding practices needs to be improved a lot in this area. Adoption of scientific and suitable housing and feeding practices of dairy animals will substantially help to increase the production as well as income generation which improve the socio economic condition of dairy keepers. So awareness camps and training programmes regarding scientific animal housing and feeding management practices will help in improving the husbandry practices in future.

\section{References}

Deoras, R. Nema, R.K., Tiwari, S.P. and Singh, M. 2004. Feeding and housing management practices of dairy animals in Rajnandagaon of Chhattisgarh plain. Indian J. Anim. Sci. 74(3): 303-306

Garg M.K, Jain L.S and Chaudry J.L. 2005. Studies on housing, feeding and milking management practices of dairy cattle in Baran district of Rajasthan. Indian Journal of Dairy Sciences 58(2): 123-28

Hodshil, S. J., Akhare, S.B., Zinjarade, R.M., Pawar, R.V., Morey, Kavita. 2007. Feeding practices adopted for Gaolao breed in Wardha District. Royal Veterinary Journal of India 2007. 3(1): 39-41

Kour, S. 2013. Farmers' profile and morphometic studies of Frieswal heifers under field progeny testing programme. M.V.Sc.
(LPM). Thesis, GBPUA\&T, Pantnagar, Uttrarakhand.

Meena, G.L., Tailor, Ravi, Sharma, F.L. 2012. Adoption of scientific Dairy Husbandry Practices by Tribal Farmers. Raj. J. Extn. Edu. 20: 121-124, 2012.

Meena, H.R., Hira, Ram., Sahoo, A. and Rasool, T.J., 2008. Livestock husbandry scenario at high altitude Kumaon Himalaya. Indian J. Anim. Sci. 78(8): 882-886.

Minu Singh, Ritu Chakravarty, Adhiti Bhanotra and Mukesh Kumar. 2015. Dairy animal health and housing management practices followed by tribal dairy farmers of Ranchi, Jharkhand. International Journal of Farm Sciences 5(3): 199-206

Sabapara G.P, Fulsoundar A.B and Kharadi V.B 2015. Existing housing management practices followed by rural dairy animal owners in Surat district of Gujarat. International Journal of Farm Sciences 5(4) : 299-308,

Sabapara, G.P., Desai, P.M., Kharadi, V.B., Saiyed, L.H. and Singh, R.R., 2010. Housing and feeding management practices of dairy animals in the tribal area of South Gujarat. Indian Journal of Animal Sciences. 2010; 80 (10):1022-1027.

Sharma, R.J. and Singh, D.V 2003. Sustainable high production of Indigenous and crossbred cattle and buffaloes in rural household under rice- wheat production system. Completion report (NATP-PSR 38) GBPUA\&T, Pantanagar.

Tiwari, H., Sanjay Kumar, Rajashree Rath and Kalpna Tyagi 2016. Existing housing and breeding management practices adopted by dairy farmers in Tarai region of Uttarakhand. Department of Livestock Production Management, College of Veterinary and Animal Sciences, G.B. Pant University of Agriculture and Technology.

\section{How to cite this article:}

Shikha Yadav, Anil Kumar and Singh, C.B. 2019. Housing and Feeding Management Practices in U.S. Nagar District of Uttarakhand. Int.J.Curr.Microbiol.App.Sci. 8(06): 2805-2810. doi: https://doi.org/10.20546/ijcmas.2019.806.338 